\title{
BIOAKUMULASI LOGAM BERAT PADA KERANG HIJAU (Perna viridis) DI PERAIRAN CIREBON BERADASARKAN MUSIM YANG BERBEDA
}

\author{
Dewi Nurhayati*1, Didha Andini Putri ${ }^{2}$, \\ ${ }^{1,2}$; Fakultas Perikanan dan Ilmu Kelautan, Universitas 17 Agustus 1945-Cirebon \\ Jl. Perjuangan No. 17 BY PASS CIREBON 45132 (0231) 486622 FAX. 90231) \\ e-mail: *11 dewinurhayati24@gmail.com
}

\begin{abstract}
Abstrak
Penelitian ini bertujuan untuk mengetahui bioakumulasi dari logam berat timbal $(\mathrm{Pb})$, kadmium $(\mathrm{Cd})$, merkuri $(\mathrm{Hg})$ pada kerang hijau (Perna viridis), sedimen, dan air pada budidaya kerang hijau di perairan Cirebon, Jawa Barat berdasarkan variasi musim yang berbeda. Penelitian dilakukan pada musim hujan (Februari) dan musim kemarau (Juli). Kerang hijau, Sedimen, dan air diambil dari tempat budidaya kerang hijau perairan bondet Cirebon. Sampel diambil pada usia panen yaitu usia 6 bulan pemeliharaan. Sampel air laut, sedimen, dan kerang hijau diambil sebanyak 3 kali ulangan. Pengujian logam berat mengikuti SNI 01-2354.6-2006. diukur di laboratorium Balai Pengujian dan Pembinaan Mutu Hasil Perikanan (BPPMHP) Cirebon, Jawa Barat. Berdasarkan hasil penelitian, kandungan Pb pada sedimen mengalami peningkatan pada musim panas dibandingkan dengan musim hujan yaitu dari $3,66 \pm 0,77 \mathrm{mg} / \mathrm{Kg}$ menjadi $5,99 \pm 0,16 \mathrm{mg} / \mathrm{Kg}(\mathrm{P}<0,05)$. Kadar $\mathrm{Pb}$ pada kerang hijau musim hujan tidak berbeda nyata dibandingkan dengan musim panas $(4,99 \pm 0,84 \mathrm{mg} / \mathrm{Kg}$ menjadi $3,77 \pm 0,75 \mathrm{mg} / \mathrm{Kg})(\mathrm{P}>0,05)$. Kadar $\mathrm{Cd}$ pada sedimen dan kerang hijau dimusim panas tidak berbeda nyata dibandingkan dengan musim hujan $(1,08 \pm 0,14 \mathrm{mg} / \mathrm{Kg}$ menjadi $0,71 \pm 0,22 \mathrm{mg} / \mathrm{Kg})(\mathrm{P}>0,05)$. Sedangkan kadar Cd pada kerang hijau musim hujan $0,87 \pm 0,14 \mathrm{mg} / \mathrm{Kg}$ lebih tinggi dibanding musim panas yaitu $0,3 \pm 0,1 \mathrm{mg} / \mathrm{Kg}(\mathrm{P}<0,05)$. Kadar $\mathrm{Hg}$ sedimen dimusim panas $(0,00 \pm 0,01)$ tidak berbeda nyata dibanding dimusim hujan $(0,05 \pm 0,06 \mathrm{mg} / \mathrm{Kg})(\mathrm{P}>0,05)$. Kadar $\mathrm{Hg}$ pada kerang hijau musim hujan $0,03 \pm 0,04 \mathrm{mg} / \mathrm{Kg}$ juga tidak menunjukkan nilai yang berbeda nyata $(\mathrm{P}>0,05)$ dibanding musim panas yaitu $0,02 \pm 0,02 \mathrm{mg} / \mathrm{Kg}$.
\end{abstract}

Kata kunci : Kerang hijau, logam berat, Cirebon, bioakumulasi

\section{BIOACCUMULATION HEAVY METAL OF GREEN MUSSEL (Perna viridis) ON CIREBON WATER BASED ON DIFFERENT SEASONS}

\begin{abstract}
Study was aim to determine the bioaccumulation of heavy metals $\mathrm{Pb}, \mathrm{Cd}$, and $\mathrm{Hg}$ in green mussels (Perna viridis), sediment, and water in the cultivation of green mussels in the waters of Cirebon, West Java based on different seasons. The study was conducted on the rainy (February) and summer (July). Green mussels, sediment, and water are taken from the cultivation of Cirebon bondet waters. Samples taken at harvest age are 6 months of maintenance. green mussels, sediment, seawater of samples were taken 3 times. Testing of heavy metals follows SNI 01-2354.6-2006 at the laboratories of the Fishery Products Quality and Testing Center (BPPMHP) Cirebon, West Java. Based on the results of the study, the Pb content in the sediment increased in the summer compared to the rainy season, ie from $3.66 \pm 0.77 \mathrm{mg} / \mathrm{Kg}$ to $5.99 \pm 0.16 \mathrm{mg} / \mathrm{Kg}(P<0.05)$. Pb levels in the rainy season green mussels were not significantly different compared to summer $(4.99 \pm 0.84 \mathrm{mg} / \mathrm{Kg}$ to $3.77 \pm 0.75 \mathrm{mg} / \mathrm{Kg})$ $(P>0.05)$. The levels of $C d$ in sediments and green mussels in summer were not significantly different compared to the rainy season $(1.08 \pm 0.14 \mathrm{mg} / \mathrm{Kg}$ to $0.71 \pm 0.22 \mathrm{mg} / \mathrm{Kg}$ ) ( $P>0.05)$. While the Cd content in the rainy season green mussels was $0.87 \pm 0.14 \mathrm{mg} / \mathrm{Kg}$ higher than the summer season which was $0.3 \pm 0.1 \mathrm{mg} / \mathrm{Kg}(P<0.05)$. The levels of $\mathrm{Hg}$ of sediment in the summer $(0.00 \pm 0.01)$ were not significantly different than in the rainy season $(0.05 \pm 0.06 \mathrm{mg} / \mathrm{Kg})(P>0.05)$. Levels of $\mathrm{Hg}$ in the rainy season green mussels $0.03 \pm 0.04 \mathrm{mg} / \mathrm{Kg}$ also did not show a significantly different value (P>0.05) compared to summer, which was $0.02 \pm 0.02 \mathrm{mg} / \mathrm{Kg}$.
\end{abstract}

Keywords: Green mussels, heavy metals, Cirebon, Bioaccumulation

\section{PENDAHULUAN}

Kerang hijau Perna viridis merupakan komoditas perikanan di perairan Cirebon yang sangat digemari oleh masyarakat. Selain kandungan gizinya yang tinggi, harganya pun lebih murah dibanding ikan, udang atau kepiting. Namun demikian kerang hijau juga merupakan komoditi perikanan yang dapat mengakumulasi logam berat dalam jumlah yang tinggi karena merupakan jenis biota laut yang bersifat filter feeder (Cordova et al., 2011). Kadar Logam berat pada kerang hijau dapat menjadi berbahaya disebabkan oleh proses bioakumulasi.

Logam berat merupakan zat yang berbahaya dan beracun jika jumlahnya melebihi ambang batas. Logam berat seperti merkuri $(\mathrm{Hg})$, timbal $(\mathrm{Pb})$ dan kadmium (Cd) adalah logam non essensial bagi tubuh, karena bersifat toksik dalam jumlah sedikit (Türkmen et al. 2008). Tingginya kandungan logam berat pada komoditi perikanan disebabkan oleh lingkungan perairan yang telah tercemar oeh limbah. Logam berat akan terdistribusi di berbagai komponen ekosistem laut dan kemudian terakumulasi oleh organisme dari sumber alam (Marsden and Rainbow 2004). Menurut Khaisar (2006) konsentrasi logam berat yang kecil akan menjadi besar (terakumulasi) pada biota trofik level rendah yang lebih tinggi, terkait dengan sistem rantai makanan. Banyak penelitian telah dilakukan pada akumulasi logam pada berbagai spesies seperti Sparus aurata, Dicentrarchus labrax and Mugil cephalus ( Dural et al., 2007), kerang hijau $P$. viridis (Cordova et al., 2011, Yaqin et al. 2015), dan European catfish Silurus glanis (Squadrone et al., 2013), Nila tilapia 
(Younis et al., 2015), dan kerang kapak-kapak (Riani et al., 2017).

Bioakumulasi berarti peningkatan konsentrasi unsur kimia tersebut dalam tubuh makhluk hidup sesuai piramida makanan (Hananingtyas, 2017). Logam berat dapat terakumulasi melalui rantai makanan, semakin tinggi tingkatan rantai makanan yang ditempati oleh suatu organisme, akumulasi logam berat di dalam tubuhnya juga semakin bertambah (Hananingtyas, 2017). Akumulasi logam berat pada biota perairan dipengaruhi oleh berbagai faktor. Diantaranya adalah ukuran, stadium perkembangan dan kadar garam pada toksisitas logam berat terhadap organisme laut dan muara (Grossel et al. 2007).

Pada penelitian sebelumnya diketahui terdapat perbedaan periodik kandungan logam berat pada spesies ikan dikarenakan oleh perbedaan musim (Afshan et al. 2014; Younis et al., 2015). Organisme pada tingkat trofik berbeda akan menunjukkan respon akumulasi logam berat yang berbeda pada tubuhnya. Belum diketahui pengaruh musim di Indonesia pada akumulasi logam berat pada kerang hijau. Karena polusi logam di lingkungan perairan bisa berbahaya bagi kesehatan manusia, maka diperlukan informasi untuk memahami pengaruh musim terhadap resiko konsumsi kerang hijau yang berasal dari wilayah perairan Cirebon. Oleh karena itu, tujuan penelitian ini adalah untuk mengetahui pengaruh musim terhadap kadar beberapa logam berat pada bivalvia jenis kerang hijau untuk menilai risiko kesehatan masyarakat yang terkait dengan konsumsi kerang dari daerah ini dengan membandingkan kandungan logam berat yang dapat ditolerir seperti yang direkomendasikan Peraturan Pemerintah no.82 tahun 2001, Kepmen LH No.51 th 2004, dan baku mutu Dirjen POM RI No. HK.00.06.1.52.4011 tahun 2009.

\section{METODE}

Pengambilan sampel berupa air laut, sedimen, dan kerang hijau (Perna viridis). Sampel air, sedimen dan kerang hijau diambil dari tempat budidaya kerang hijau perairan bondet Cirebon yaitu sekitar $2 \mathrm{~km}$ dari garis pantai. Sampel diambil pada musim hujan dibulan Februari pada usia panen yaitu usia 6 bulan pemeliharaan. Sampel air laut, sedimen, dan kerang hijau diambil sebanyak 3 kali ulangan. Sampel air laut diambil pada lapisan permukaan $(30 \mathrm{~cm}$ di bawah permukaan laut) dan dimasukkan ke dalam botol kaca (volume $\pm 100 \mathrm{ml}$ ). Sampel sedimen diambil dari dasar perairan tepat di bawah bagan tancap tempat budidaya kerang hijau. Sampel kerang diambil sebanyak 5 ekor pada setiap ulangan. Setelah itu sampel air, sedimen dan kerang hijau dimasukkan ke dalam cool box selama transportasi ke laboratorium.

Sampel diukur di laboratorium Balai Pengujian dan Pembinaan Mutu Hasil Perikanan
(BPPMHP) Cirebon, Jawa Barat untuk dilakukan pengukuran kadar logam berat. Pengujian logam berat mengikuti SNI 01-2354.6-2006. Pembacaan sampel dilakukan dengan alat AAS (GBC Avanta 932 AA) (Atomic Absorption Spectrophotometer).

Analisis Statistik

Penelitian ini menggunakan rancangan percobaan berupa Rancangan Acak Lengkap dengan tiga ulangan. Data yang diperoleh dianalisis dengan menggunakan analisis ragam dengan tingkat kepercayaan $95 \%$ dengan menggunakan program komputer SPSS 17.

\section{HASIL DAN PEMBAHASAN}

\section{Kadar Logam Berat Timbal (Pb), Kadmium (Cd) dan Merkuri (Hg) pada Sedimen dan Kerang Hijau $P$. viridis}

Berdasarkan hasil penelitian kadar logam berat timbal $(\mathrm{Pb})$ pada sedimen dan kerang hijau (Gambar 1), diketahui kandungan logam berat timbal pada sedimen mengalami peningkatan pada musim panas dibandingkan dengan musim hujan yaitu dari $3,66 \pm 0,77 \mathrm{mg} / \mathrm{Kg}$ menjadi $5,99 \pm 0,16 \mathrm{mg} / \mathrm{Kg}$ dan memberikan hasil yang berbeda nyata $(\mathrm{P}<0,05)$. Sedangkan kadar logam berat pada kerang hijau musim hujan mengalami penurunan dibandingkan dengan musim panas yaitu dari $4,99 \pm 0,84 \mathrm{mg} / \mathrm{Kg}$ menjadi $3,77 \pm 0,75 \mathrm{mg} / \mathrm{Kg}$ namun tidak berbeda nyata antara musim hujan dan musim panas $(\mathrm{P}>0,05)$.

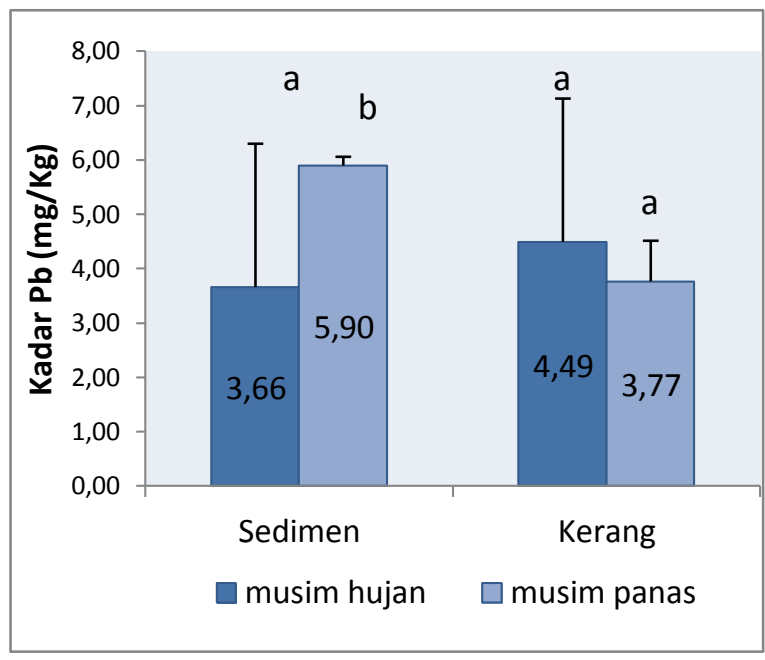

keterangan:* Huruf superscript yang berbeda menunjukkan hasil yang berbeda nyata $(\mathrm{P}<0,05)$

Gambar 1. Kadar logam berat timbal (Pb) pada sedimen dan kerang hijau di musim hujan dan musim panas

Sementara itu hasil penelitian kadar logam berat kadmim $(\mathrm{Cd})$ pada sedimen dan kerang hijau (Gambar 2) dimusim panas mengalami penurunan dibandingkan dengan musim hujan yaitu dari $1,08 \pm 0,14 \mathrm{mg} / \mathrm{Kg}$ menjadi $0,71 \pm 0,22 \mathrm{mg} / \mathrm{Kg}$, namun tidak menunjukkan hasil yang berbeda nyata $(\mathrm{P}>0,05)$. Sedangkan kadar logam berat $\mathrm{Cd}$ pada 
kerang hijau musim hujan $0,87 \pm 0,14 \mathrm{mg} / \mathrm{Kg}$ lebih tinggi dibanding musim panas yaitu $0,3 \pm 0,1 \mathrm{mg} / \mathrm{Kg}$ dan menunjukkan nilai yang berbeda nyata $(\mathrm{P}<0,05)$.

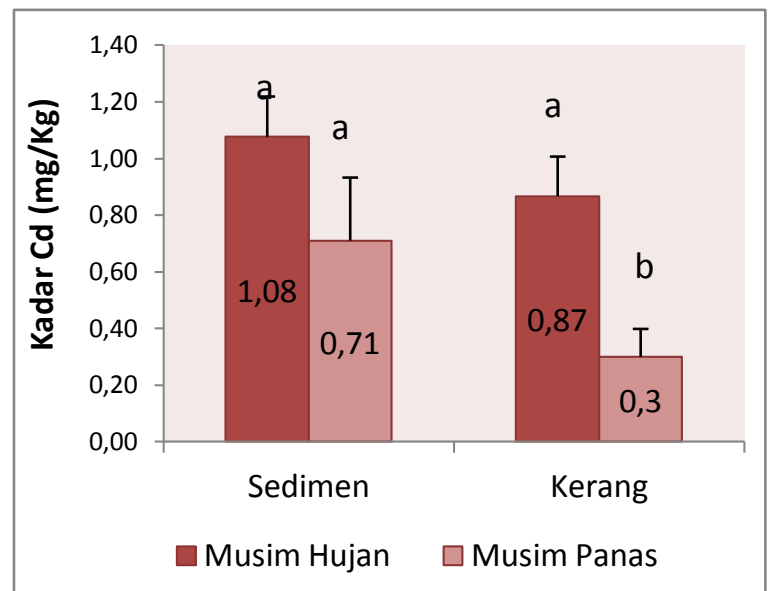

keterangan: * Huruf superscript yang berbeda menunjukkan hasil yang berbeda nyata $(\mathrm{P}<0,05)$

Gambar 2. Kadar logam berat kadmium (Cd) pada sedimen, kerang hijau, dan air di musim hujan dan musim panas

Kadar logam berat lainnya, diketahui konsentrasi merkuri ( $\mathrm{Hg})$ sedimen (Gambar 3) dimusim panas sebesar $0,00 \pm 0,01$ dan mengalami kenaikan dimusim hujan yaitu $0,05 \pm 0,06 \mathrm{mg} / \mathrm{Kg}$, namun tidak menunjukkan hasil yang berbeda nyata $(\mathrm{P}>0,05)$. Sedangkan kadar logam berat $\mathrm{Hg}$ pada kerang hijau musim hujan $0,03 \pm 0,04 \mathrm{mg} / \mathrm{Kg}$ juga tidak menunjukkan nilai yang berbeda nyata $(\mathrm{P}>0,05)$ dibanding musim panas yaitu $0,02 \pm 0,02 \mathrm{mg} / \mathrm{Kg}$.

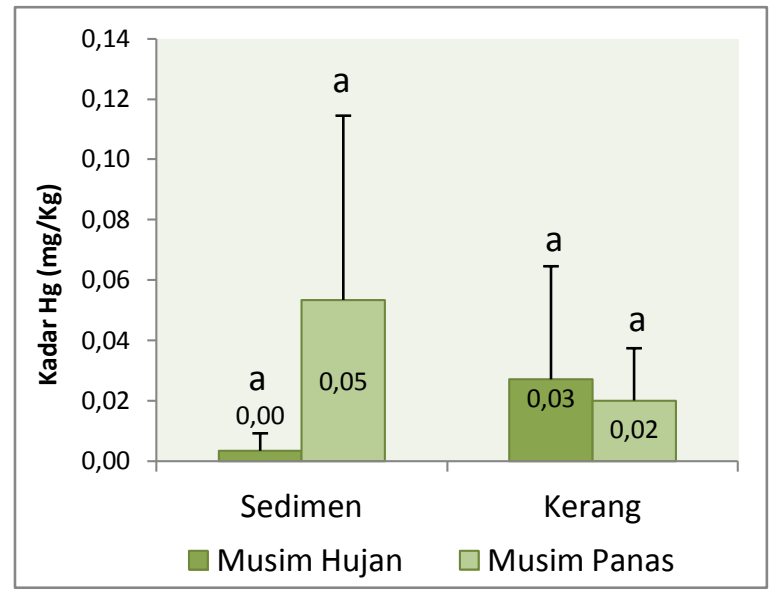

keterangan:

* Huruf superscript yang berbeda menunjukkan hasil yang berbeda nyata $(\mathrm{P}<0,05)$

Gambar 3. Kadar logam berat merkuri (Hg) pada sedimen dan kerang hijau di musim hujan dan musim panas

Perbedaan konsentrasi logam berat $\mathrm{Pb}, \mathrm{Cd}$, dan $\mathrm{Hg}$ pada sedimen antara musim panas dan musim hujan dipengaruhi oleh berbagai faktor. Diantaranya adalah proses fisik. Proses fisik dipengaruhi oleh kondisi lingkungan seperti arus yang mempengaruhi laju pengendapan. Pada musim hujan diduga arus menyebabkan terjadinya gesekan antara permukaan sedimen dengan massa air. Hal ini menyebabkan terlepasnya partikel dalam sedimen ke kolom perairan, sehingga berpotensi menurunkan atau menaikkan konsentrasi konsentrasi logam berat dalam partikel tersuspensi (Palar 2009) Besarnya kandungan logam berat pada sedimen di perairan ini masih berada dibawah baku mutu standar internasional menurut Dutch Quality Standard For Metals in Sediments yaitu dengan konsentrasi maksimum 85 mg/Kg (IADC/DECA 1997).

Kadar logam berat $\mathrm{Pb}, \mathrm{Cd}$, dan $\mathrm{Hg}$ pada kerang hijau di Perairan Cirebon ini seluruhnya mengalami penurunan apabila dibandingkan dengan musim hujan. Pada penelitian Younis et al. (2015) yang menunjukkan bahwa jenis logam berat $\mathrm{Pb}$ pada ikan tertinggi terdapat pada musim summer>winter>spring>autumn, sedangkan kadar logam berat kadmium tertinggi terdapat pada winter >spring >autumn > summer. Berdasarkan persyaratan mutu kerang di Indonesia menurut keputusan menteri Surat Keputusan Direktur Jenderal Pengawasan Obat dan Makanan RI No. HK.00.06.1.52.4011 Tahun 2009, besarnya kandungan logam berat $\mathrm{Pb}$ telah melebihi ambang batas yaitu yaitu $3,77 \pm 0,75 \mathrm{mg} / \mathrm{Kg}$ dan $4,99 \pm 0,84$ $\mathrm{mg} / \mathrm{Kg}$ sedangkan besarnya kandungan logam berat $\mathrm{Cd}$ dan $\mathrm{Hg}$ masih sesuai dengan persyaratan mutu. Dengan demikian kandungan logam $\mathrm{Pb}$ ini harus menjadi perhatian bersama. Standar BPOM mensyaratkan agar konsentrasi kadmium pada bahan makanan kekerangan $<1,0 \mathrm{mg} / \mathrm{kg}$ dan mensyaratkan agar konsentrasi timbal pada bahan makanan $<1,5$ $\mathrm{mg} / \mathrm{Kg}$, dan $\mathrm{Hg}<0,06 \mathrm{mg} / \mathrm{Kg}$.

Kadar Logam Berat Timbal (Pb), Kadmium (Cd) dan Merkuri (Hg) pada Perairan Cirebon

Berdasarkan hasil pengukuran kadar logam berat di perairan (Tabel 2), konsentrasi logam berat $\mathrm{Pb}, \mathrm{Cd}$, dan $\mathrm{Hg}$ diperairan antara musim hujan dan musim panas tidak menunjukkan hasil yang berbeda nyata $(\mathrm{P}>0,05)$. Konsentrasi $\mathrm{Pb}$ menunjukkan hasil yang tinggi pada musim panas yaitu $0,04 \pm 0,07 \mathrm{mg} / \mathrm{L}$,

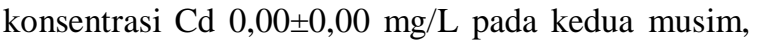
dan konsentrasi $\mathrm{Hg}$ menunjukkan hasil 0,03 $\pm 0,02$ $\mathrm{mg} / \mathrm{L}$ pada musim hujan dan $0,07 \pm 0,03 \mathrm{mg} / \mathrm{L}$.

Tabel 1. Kadar logam berat $\mathrm{Pb}, \mathrm{Cd}$, dan $\mathrm{Hg}$ di Perairan Cirebon

\begin{tabular}{lccc}
\hline & $\begin{array}{c}\text { Logam Berat } \\
\mathrm{Pb}(\mathrm{mg} / \mathrm{L})\end{array}$ & $\begin{array}{c}\text { Logam Berat } \\
\mathrm{Cd}(\mathrm{mg} / \mathrm{L})\end{array}$ & $\begin{array}{c}\text { Logam Berat } \\
\mathrm{Hg}(\mathrm{mg} / \mathrm{L})\end{array}$ \\
\hline $\begin{array}{l}\text { Musim } \\
\text { Hujan } \\
\text { Musim } \\
\text { Panas }\end{array}$ & $0,00 \pm 0,00^{\mathrm{a}}$ & $0,00 \pm 0,00^{\mathrm{a}}$ & $0,03 \pm 0,02^{\mathrm{a}}$ \\
\hline
\end{tabular}

keterangan:* Huruf superscript yang berbeda menunjukkan hasil yang berbeda nyata $(\mathrm{P}<0,05)$ 
Adanya arus dan gerakan pasang surut air laut juga mempengaruhi tingginya kandungan logam berat. Apabila pada saat pasang nelayan mengambil ikan maka keadaan air laut pada saat itu dapat dimungkinkan mengandung tinggi logam berat dari cemaran limbah yang dibuang di muara dan daerah sungai. Adanya pasang surut ini menggerakkan massa air secara horizontal, sehingga terjadi pencampuran (Palar, 2009). Pada musim hujan volume air yang masuk ke dalam laut lebih tinggi daripada musim panas, baik itu berasal dari sungai maupun dari air hujan. Menurut Keputusan Menteri Lingkungan Hidup (KMNLH) Nomor 51 tahun 2004 tentang baku mutu air laut untuk biota laut yaitu $\mathrm{Cd}$ dan $\mathrm{Hg}$ adalah $0,001 \mathrm{mg} / \mathrm{L}$, sedangkan $\mathrm{Pb}$ sebesar 0,008 mg/L. Dengan demikian nilai baku mutu air laut di perairan bondet Cirebon ini telah mengalami kontaminasi $\mathrm{Pb}$ dan $\mathrm{Hg}$ khususnya pada pengujian dimusim panas. Konsentrasi $\mathrm{Pb}$ di perairan bondet ini tidak jauh berbeda dengan penelitian Santoso (2014) yang menunjukkan bahwa konsentrasi logam berat $\mathrm{Pb}$ dalam air mencapai 0.061-0.065 mg/L.

Perairan Cirebon ini juga tidak terdeteksi adanya konsentrasi logam berat $\mathrm{Cd}$. Diduga $\mathrm{Cd}$ terbawa arus dan terakumulasi di dalam sedimen. Keberadaan arus dan gelombang air laut yang cukup kuat di sekitar lokasi pengamatan diduga berperan dalam menentukan keberadaan logam berat di perairan, karena arus yang dapat mengaduk massa air yang ada di dekat dasar perairan maupun yang berada di sedimen (Khaisar 2006). Menurut Younis et al. (2015), Perbedaan musim memberikan pengaruh perubahan terhadap kondisi lingkungan di badan air. Selain itu kualitas air dapat dipengaruhi oleh sumber air, laju aliran, nutrisi dan alga. Faktor lainnya adalah adanya limbah dan buangan dari pertanian, bahan kimia berbahaya dan kontaminan alami (misalnya feses hewan) mencapai sumber air alami yang dapat mencemari air tanah dengan rembesan.

\section{Hubungan antara Konsentrasi Logam Berat $\mathbf{P b}$, Cd, dan Hg dalam Sedimen Laut dan Kerang Hijau Perna viridis}

Korelasi logam berat timbal $(\mathrm{Pb})$ antara sedimen dan kerang hijau dimusim hujan dan musim panas memiliki niai yang tinggi yaitu mencapai 0,810 dan 0,993 (Tabel 2). Nilai korelasi menunjukkan bahwa $\mathrm{Pb}$ memiliki korelasi yang kuat antara sedimen dan kerang hijau $(>0,5)$. Keberadaan $\mathrm{Pb}$ dikerang hijau dipengaruhi konsentrasi $\mathrm{Pb}$ disedimen meskipun musim hujan menunjukkan koefisien determinasi yang lebih rendah dibanding musim panas yaitu mencapai $98,7 \%$.

Sedangkan korelasi logam berat kadmium (Cd) antara sedimen dan kerang hijau dimusim hujan dan musim panas juga memiliki niai yang tinggi yaitu mencapai 0,994 dan 0,896 (Tabel 2). Nilai korelasi menunjukkan bahwa $\mathrm{Cd}$ memiliki korelasi yang kuat antara sedimen dan kerang hijau $(>0,5)$. Keberadaan $\mathrm{Cd}$ dikerang hijau dipengaruhi konsentrasi $\mathrm{Cd}$ disedimen dengan koefisien determinasi yang juga tinggi baik dimusim hujan maupun dimusim panas yaitu mencapai $98,8 \%$ dan $80,4 \%$.

Korelasi logam berat merkuri antara sedimen dan kerang hijau dimusim hujan dan musim panas juga memiliki niai yang tinggi yaitu mencapai 0,991 dan 0,756 (Tabel 2). Nilai korelasi menunjukkan bahwa $\mathrm{Hg}$ memiliki korelasi yang kuat antara sedimen dan kerang hijau $(>0,5)$. Akan tetapi koefisien determinasi $\mathrm{Hg}$ dikerang hijau dan disedimen pada musim hujan menunjukkan nilai lebih tinggi dibanding musim panas. Masing-masing senilai $98,3 \%$ dan $57,1 \%$.

Konsentrasi logam berat dalam substrat/sedimen secara alami menggambarkan keberadaan logam berat tertentu/deposit mineral. Logam berat di perairan seringkali dihubungkan dengan partikel tersuspensi dan sedimen, bahkan sedimen lebih stabil atau kurang mobilitasnya dibandingkan dengan kolom air (Riani et al 2017). Sedangkan kerang hijau hidup sebagai filter feeder yang memfilter partikel-partikel yang ada di perairan tempat mereka hidup. Di samping itu kerang hijau adalah organisme yang mempunyai pergerakan yang minimal di perairan atau yang dikenal dengan sedentary animal, sehingga tidak dimungkinkan menghindari bahan pencemar yang mencemari lingkungan hidupnya (Yaqin et al. 2015), khususnya pencemar yang terdapat pada sedimen.

Tabel 2. Korelasi Logam Berat Pb, Cd, dan Hg dalam Sedimen Laut dan Kerang Hijau Perna viridis

\begin{tabular}{lllcc}
\hline Jenis Logam Berat & Musim & \multicolumn{3}{c}{ Analisis Regresi } \\
\cline { 3 - 5 } & & Persamaan & $\mathrm{R}(\%)$ & $\mathrm{r}$ \\
\hline Timbal $(\mathrm{Pb})$ & Hujan & $\mathrm{y}=1,291+0,875 \mathrm{x}$ & 65,6 & 0,810 \\
& Panas & $\mathrm{y}=-23,463+4,618 \mathrm{x}$ & 98,7 & 0,993 \\
\hline Kadmium $(\mathrm{Cd})$ & Hujan & $\mathrm{y}=1,817-0,883 \mathrm{x}$ & 98,8 & 0,994 \\
& Panas & $\mathrm{y}=0,612-0,440 \mathrm{x}$ & 80,4 & 0,896 \\
\hline Merkuri $(\mathrm{Hg})$ & Hujan & $\mathrm{y}=0,005+6,5 \mathrm{x}$ & 98,3 & 0,991 \\
& Panas & $\mathrm{y}=0,031-0,214 \mathrm{x}$ & 57,1 & 0,756 \\
\hline
\end{tabular}

Keterangan: $\mathrm{y}=$ nilai logam berat di kerang hijau; $\mathrm{x}=$ nilai logam berat di sedimen, $\mathrm{R}=$ koefesien determinasi; $\mathrm{r}=$ koefesien korelasi 


\section{SIMPULAN}

Berdasarkan hasil penelitian disimpulkan bahwa musim berpengaruh terhadap kadar logam berat kadmium, tetapi tidak berpengaruh terhadap kadar logam berat timbal dan merkuri pada bivalvia jenis kerang hijau. Namun demikian musim juga berpengaruh terhadap kandungan kadar logam berat timbal pada sedimen laut yang berkorelasi kuat terhadap kandungan logam berat pada kerang hijau. Besarnya kandungan logam berat $\mathrm{Pb}$ pada kerang hijau telah melebihi ambang batas aman yaitu $3,77 \pm 0,75 \mathrm{mg} / \mathrm{Kg}$ dan 4,99 $\pm 0,84 \mathrm{mg} / \mathrm{Kg}$.

\section{UCAPAN TERIMA KASIH}

Penelitian ini merupakan bagian dari Penelitian Dosen Pemula (PDP) tahun 2017-2018 yang didanai oleh Kemenristekdikti. Ucapan terima kasih diberikan kepada pihak Kemenristekdikti dan semua rekan yang telah terlibat dalam penelitian.

\section{DAFTAR PUSTAKA}

Afshan,S., Ali, S., Ameen, U.S., Farid, M., Bharwana, S.A., Hannan, F., Ahmad R. (2014). Effect of Different Heavy Metal Pollution on Fish. Res. J. Chem. Env. Sci. 2 (1): 74-79.

[BPOM] Badan Pengawas Obat Dan Makanan Republik Indonesia. (2009). HK.00.06.1.52.4011 Tahun 2009. Penetapan Batas Maksimum Cemaran Mikroba dan Kimia Dalam Makanan. Jakarta: Badan Pengawas Obat Dan Makanan Republik Indonesia.

Cordova, M.R., Zamani, N.P., Yulianda, F. (2011). Akumulasi Logam Berat pada Kerang Hijau (Perna viridis) Di PerairanTeluk Jakarta. Jurnal Moluska Indonesia. 2(1): 1-8.

Dural, M., Goksu, M.Z.L., Ozak, A.A. (2007). Investigation of Heavy Metal Levels in Economically Important Fish Species Captured from The Tuzla Lagoon. Food Chem, 102: 415-421.

Grosell, M., Blanchard, J., Brix, K., Gerdes, R. (2007). Physiology is Pivotal for Interactions Between Salinity and Acute Copper Toxicity to Fish and Invertebrates. Aqu.Toxicol. 84:162-172.

Hananingtyas, I. 2017. Studi Pencemaran Kandungan Logam Berat Timbal $(\mathrm{Pb})$ dan Kadmium $(\mathrm{Cd})$ pada Ikan Tongkol (Euthynnus sp.) di Pantai Utara Jawa. Biotropic the journal of tropical biology, 1(2):41-50.
IADC/CEDA. 1997. Convention, Codes, and Conditions: Marine Disposal. Enviromental Aspects of Dredging 2a.71 hal.

Khaisar O. (2006). Kandungan timah hitam (pb) dan kadmium (cd) dalam air, sedimen, dan bioakumulasi serta respon histopatologis organ ikan alu-alu (Sphyraena barracuda) di perairan Teluk Jakarta [skripsi]. Bogor (ID):

Departemen Manajemen Sumberdaya Perairan Fakultas Perikanan dan Ilmu

Kelautan-Institut Pertanian Bogor.

[Kepmen LH] Keputusan Menteri Lingkungan Hidup. No. 51 tahun 2004. (2004). Tentang "Penetapan Baku Mutu Air Laut". Jakarta: Keputusan Menteri Lingkungan Hidup.

Marsden ID, Rainbow PS. (2004). Does the accumulation of tracemetals in crustaceans affect their ecology. J. Exp. Mar. Biol. Ecol. 300: $373-408$.

Palar, H. (2008). Pencemaran dan Toksikologi Logam Berat. Jakarta: Rineka Cipta.

Riani, E., Johari, H.S., Cordova, M.R. (2017). Bioakumulasi Logam Berat Kadmium dan Timbal pada Kerang Kapak-Kapak di Kepulauan Seribu. Jurnal Pengolahan Hasil Perikanan, 20(1): 131-142.

Santoso LP. 2014. Kandungan logam berat timbal ( $\mathrm{Pb})$ dan kadmium $(\mathrm{Cd})$ pada sedimen dan air di perairan Pelabuhan Kejawanan, Cirebon [skripsi]. Bogor (ID): Departemen Ilmu dan Teknologi Kelautan Fakultas Perikanan dan Ilmu Kelautan-Institut Pertanian Bogor.

Squadrone, S., Prearo, M., Brizio, P., Gavinelli, S., Pellegrino, M., Scanzio, T., Guarise, S., Benedetto, A., Abete, M.C. (2013). Heavy Metals Distribution in Muscle, Liver, Kidney and Gill of European Catfish (Silurus glanis) from Italian Rivers. Chemosphere, 90: 358365.

Turkmen, M., Turkmen, A., Tepe, Y., Ates, A., Kkus, G.K. (2008). Determination of Metal Contaminations in Sea Foods from Marmara, Aegean and Mediterranean Seas: Twelve Fish Species. Food Chem, 108: 794-800.

Yaqin, K., Fachruddin, L., Rahim, N.F. (2015). Studi Kandungan Logam Timbal (Pb) Kerang Hijau, Perna viridis Terhadap Indeks Kondisinya. Jurnal Lingkungan Indonesia, 3(6):309-317.

Younis, E.M., Al-Asgah, N.A., Abdel-Warith , A.W.A., Al-Mutairi, A.A. (2015). Seasonal Variations in the Body Composition and Bioaccumulation of Heavy Metals in Nile Tilapia Collected from Drainage Canals in AlAhsa, Saudi Arabia. Saudi Journal of Biological Sciences, 22: 443-447. 